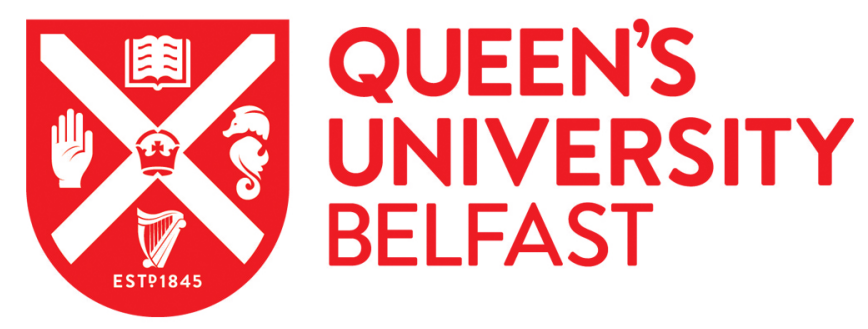

\title{
Connectivity and Physical Activity: Using Footpath Networks to Measure the Walkability of Built Environments
}

Ellis, G., Hunter, R. F., Tully, M., Donnelly, M., Kelleher, L., \& Kee, F. (2016). Connectivity and Physical Activity: Using Footpath Networks to Measure the Walkability of Built Environments. Environment and Planning B: Planning and Design, 43(1), 130-151. https://doi.org/10.1177/0265813515610672

Published in:

Environment and Planning B: Planning and Design

Document Version:

Peer reviewed version

Queen's University Belfast - Research Portal:

Link to publication record in Queen's University Belfast Research Portal

\section{Publisher rights}

Copyright 2015 Ellis et al,.

The definitive, peer-reviewed and edited version of this article is published in Environment and Planning B, volume 43, issue 1, 2016, DOI:10.1177/0265813515610672.

\section{General rights}

Copyright for the publications made accessible via the Queen's University Belfast Research Portal is retained by the author(s) and / or other copyright owners and it is a condition of accessing these publications that users recognise and abide by the legal requirements associated with these rights.

Take down policy

The Research Portal is Queen's institutional repository that provides access to Queen's research output. Every effort has been made to ensure that content in the Research Portal does not infringe any person's rights, or applicable UK laws. If you discover content in the Research Portal that you believe breaches copyright or violates any law, please contact openaccess@qub.ac.uk. 
Geraint Ellis ${ }^{\mathrm{ac}}$, Ruth F. Hunter ${ }^{\mathrm{bc}}$, Mark A Tully ${ }^{\mathrm{bc}}$, Michael Donnelly ${ }^{\mathrm{a}}$, Luke Kellehera, and Frank Kee ${ }^{\mathrm{bc}}$.

aSchool of Planning, Architecture and Civil Engineering, Queen's University Belfast.

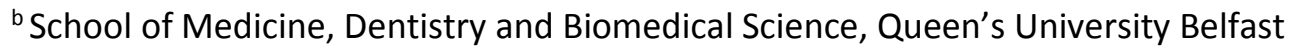

'UKCRC Centre for Excellence in Public Health, Queen's University Belfast

Corresponding Author:

Prof. Geraint Ellis

School of Planning, Architecture and Civil Engineering

Queen's University, Belfast,

David Keir Building

Stranmillis Rd

Belfast

BT9 5AG

Tel: (+44) 02890974370

e-mail: g.ellis@qub.ac.uk 


\section{CONNECTIVITY AND PHYSICAL ACTIVITY: USING FOOTPATH NETWORKS TO MEASURE THE WALKABILITY OF BUILT ENVIRONMENTS}

\section{Introduction}

The scale of the obesity crisis obesity is considerable and in the UK alone it has been estimated to cost the NHS $f 1.06$ billion per annum (Allender et al 2007) and it is responsible for nearly $10 \%$ of all deaths from non-communicable diseases worldwide (Kohl et al 2012, Lee et al 2012). High levels of obesity are influenced by numerous factors interacting in complex ways (Butland et al 2007; Guthman, 2013), with decreasing levels of physical activity being a key factor (Bauman et al; 2012). Although the drivers for securing a sustained increase in physical activity behaviour are still not fully understood (NICE 2012), there is growing evidence to suggest that built environment features can have some influence (Sallis et al 2012). Recent research has provided important empirical and conceptual insights into how we may begin to design interventions that will promote a healthier approach to urban planning. "Walkability" has been used as a descriptor of how conducive an urban environment may be for physical activity and attempts have been made to capture those built environment characteristics that are associated with this in the form of a single 'Walkability Index' (Leslie et al 2007, Frank et al 2010). Although conceptually simple and having strong explanatory features, a number of aspects of this Index can limit its accuracy and applicability, thus potentially constraining its usefulness for practitioners.

Drawing on a case study from Belfast, this paper specifically reviews the concept of 'connectivity' when assessing the walkability of the built environment in those cases where footpaths are used instead of roads as components of the Walkability Index. In such cases it is necessary to review whether the accuracy of the Index can be improved by adopting alternative measures of connectivity to better reflect how pedestrians navigate the built environment. This paper explains the context in which a GIS-based footpath network was developed in Belfast and then evaluates six measures of connectivity by identifying those most closely associated with actual levels of physical activity.

\section{Walkability of the Built Environment}

Since the mid-1990s there has been increasing research interest in how the built environment encourages physical activity (estimated at over 200 studies in the previous decade by Bull et al 2010). This body of research suggests that certain features of the built environment, such as mixed land uses, are positively (or negatively) associated with walking (Bauman et al 2012, Ding and Gebel 2012),. Clearly, the relationship between individual physical activity and the built environment is not simple, with a high 
degree of variance between actual types of activity, temporal variations and differential impacts according to age and other demographic characteristics (Villanueva et al, 2013). The relationship between the built environment and physical activity has led to the idea of 'walkability' defined as "the extent to which the built environment supports and encourages walking by providing for pedestrian comfort and safety, connecting people with varied destinations within a reasonable amount of time and effort and offering visual interest in journeys throughout the network" (Southworth 2005, p. 248). Walkability is particularly associated with incidental physical activity, i.e. active travel. Regular walking has been associated with a wide range of health benefits (Hamer and Chida, 2008, Murphy et al 2007) and as an active form of travel addresses the traditional concerns of planners, including the need for efficient and sustainable transport, reduced traffic congestion, improved air quality, enhanced local economies and more inclusive communities. There is therefore a strong case for understanding how best to measure and monitor walkability.

\section{Assessing Walkability}

As noted above, there is a large number of studies that have examined the environmental attributes associated with walkability and while these will not be comprehensively reviewed here (see Owen et al 2004, Giles Corti et al 2013), there is broad consensus that an area will encourage walking if it exhibits high degrees of proximity (i.e. many functions are within walking distance) and connectivity (i.e. allowing easy and direct routes between destinations). Southworth (2005 p. 249), amongst others, has suggested that some of the features that best reflect these attributes are: dense networks of footpaths; linkages with public transport; fine grained mix of land uses; safety (from crime and road accidents); and high environmental quality with high visual interest and good street design. Brownson et al (2009), provide an overview of the tools for assessing walkability categorising them into: self-reported subjective assessments based on individuals' perceptions (Joes et al 2008); observational measures, based on audits of physical environments (such as NEWS, Cerin et al 2006); and analysis of the built environment using Geographic Information Systems (GIS), using existing spatial data to produce "objective" assessments.

Although there can be mismatches between subjective and objective measures of walkability (e.g. van Lenthe and Kamphuis, 2011), it has been suggested that 'objective' measures, such as GIS measures have the best association with walkability (Lin and Moudon, 2010, Hajna et al 2013). Indeed, GIS analyses have other advantages, including rapid assessment of large areas, comparative evaluation within and across urban areas and because most statutory agencies have GIS-capability, they have potential for developing 
effective decision-support tools. This can be further facilitated by representing the complexities of environment-behaviour relationships as a simple, robust, verifiable and reproducible indicator, such as the Walkability Index ${ }^{1}$ (Leslie et al 2007, Frank et al 2010, International Physical Activity and the Environment Network, IPEN²), based on the following attributes:

1. Residential Density;

2. Retail Floor Area Ratio, representing the retail building floor area divided by the retail land site area;

3. Land use mix, based on five categories (residential, retail, entertainment, office and institutional) and calculated using a entropy equation;

4. Street Connectivity, using Intersection Density based on road centre lines calculated as the ratio between the number of road intersections of three of more legs and the land area.

While the Walkability Index provides a useful and relatively simple means of capturing the broad features that appear to influence physical activity for utility journeys, it does have a number of drawbacks. This includes the fact that, as noted by Bull (2010), the Index has been developed and deployed primarily in a North American and Australian context, which have distinct urban morphologies. There is therefore a need to refine and further test such tools in more diverse urban environments, such as those that exist in Europe or the Global South (Grasser et al 2013). Although most of the components of the Index are readily available from transport or census authorities, this is not always the case (e.g. retail floor areas is often difficult to obtain in a UK context). We must also remember that the Index is a measure of relative, not absolute, walkability and tends to indicate factors that may encourage or facilitate walking behaviour but does not identify the main causal links in any particular area, nor account for the wide range of demographic and cultural influences on walking.

In some circumstances, the availability of data may limit the use of the Index as a decision-support tool for planning and transport decisions. For example, road centre lines tend to be used as a proxy for pedestrian connectivity due to almost universal availability, thus displacing the needs for primary data collection. In the case of some urban morphologies, road centre lines broadly mirror the entire pedestrian network with most footpaths being sidewalks along roads. This is particularly the case in the gridiron and hyper-suburban urban landscapes of North American and Australia, from where most physical activity studies emanate (Schilling et al 2009). However in other urban forms, such as those with many segregated

\footnotetext{
${ }^{1}$ This is calculated using the expression Walkability $=[(2 x z$-intersection density $)+(z-n e t$ residential density $)+(z-$ retail floor area ration) $+(z-l a n d ~ u s e ~ m i x)$

${ }^{2}$ http://www.ipenproject.org/methods gis.html\#Measures
} 
walkways or high levels of publicly accessible open space, it is likely that the road centre line will perform less well as a proxy of pedestrian connectivity and therefore potentially induce distortions to the Walkability Index. This has added significance given that IPEN and Frank et al (2010) double weight connectivity in the Walkability Index. There are also issues related to the spatial scale of analysis (Learnihan et al 2011) as road networks are often unable to reflect the finer-grained paths chosen by pedestrians (such as cut-through at the end of cul-de-sacs) or some types of short walking trips (lacono et al 2010). Most critically, road centre lines are inappropriate for some policy-based analytical tasks, such as evaluating the potential impact of developing new pedestrian infrastructure like greenways or footbridges, as before/after differences are not registered on the road network. This problem of "missing pedestrian data" has been highlighted by Chin et al (2008), who assessed its significance in a study of Perth, Australia, finding that measures of connectivity for some neighbourhoods improved by up to $120 \%$ using pedestrian networks compared to road networks. Tal and Handy (2012) also measured the connectivity of what they called "non-motorised" connectivity in Davis, California by augmenting the street network with off-street paths. They found that by using only the street network the number of households within a 5 -minute walk from some destinations was underestimated by as much as $40 \%$. They also suggested that using footpaths could mean that suburban areas are better connected than high density gird blocks, counter to conventional wisdom, but that evidence from a wider range of settings was needed to further explore such issues. However, the studies of neither Chin et al (2008) nor Tal and Handy (2012) were validated against actual physical activity behaviour. This lack of validation leaves us with an incomplete understanding of whether it is worth replacing road centre lines with footpath networks in practical applications for active travel interventions.

Furthermore, once a decision has been made to replace the road lines with the footpath network, one must then review how the connectivity of the network is best represented in the Walkability Index. When using road centre lines, convention has dictated that Intersection Density represents the best reflection of connectivity, yet a switch to footpath networks opens up a range of alternative connectivity measures that could potentially more accurately reflect pedestrian activity. While there is a literature on the various permutations of connectivity, these have not yet been evaluated as part of a Walkability Index based on the footpath network and validated against physical activity data. It is for these reasons that, as part of a major study of new infrastructure in Belfast (Northern Ireland), a comprehensive footpath network was mapped, six different measures of connectivity calculated and tested against measured levels of physical activity within the local community, as described in the next section. 


\section{Case Study: PARC's 'Real Walkable Network’?}

The Physical Activity and the Rejuvenation of Connswater (PARC) Study (Tully et al 2013) is evaluating the public health impact of Connswater Community Greenway (CCG), a major urban regeneration project in Belfast (see Figure 1). The aim of the CCG is to offer enhanced opportunities for physical activity and outdoor recreation through specific environmental improvements including the construction of $19.4 \mathrm{~km}$ of new cycle and walkways and the provision of recreational facilities and allotments. The PARC study area comprises 64 Super Output Areas in 29 wards surrounding the new Greenway and includes 43639 dwellings and a population of 89413. One element of the PARC study seeks to evaluate the influence of the built environment on the health of local residents, before and after the construction of the Greenway. In order to ascertain this, a baseline study was undertaken of the environmental features in the area. This included mapping the complete footpath network for the surrounding the new Greenway. Given that no network data is collected on footpaths in Northern Ireland (unlike, for example other parts of the UK ${ }^{3}$ ) this had to be mapped afresh, using the existing map base provided under a research agreement by the Land and Property Services of Northern Ireland ${ }^{4}$ cross-checked against aerial photographs, other online sources and field visits. Our Real Walkable Network ("RWN", as we have called it) is 761km in length with over 30,000 elements in the study area and a detail of the network is shown in Figure 2. Many of the issues encountered when mapping this network are discussed by Tal and Handy (2012) and not further elaborated here. Where footpaths intersected a road we provided an the option for crossing at this point, whether a formally designated pedestrian crossing or not (as shown in Figure 2), which differs from the approach of Tal and Handy (2012) when developing their "non-motorised network". Road crossings were modelled based on the assumption that at any path junction a decision must be made by an individual to either continue in the same direction, return the way they came or to select one of the other available avenues open to them. It was common for at least one or more of the possible options available to include crossing a road. The assumption was then made that someone crossing the road would take the shortest route across from their current location at a junction to the nearest junction in their line of travel to their destination. Formal road crossing such as Zebra, and Pelican crossings were not modelled due to the unavailability of the data. This is shown on Figure 2 and has consequences for the number of nodes included in the network and as discussed below, some of the measures of connectivity. Digitising errors

\footnotetext{
${ }^{3}$ See for example, the Ordnance Survey's Urban Path Theme, http://www.ordnancesurvey.co.uk/oswebsite/products/os-mastermap/itn-layer/urban-paths.html ${ }^{4}$ See http://www.dfpni.gov.uk/lps/index/gi.htm
} 
were minimised by peer quality assurance checks, field visits and the use of network models to check typologies. We believe this process has largely overcome the common errors that are found to exist with road data (Frizelle et al 2009) and therefore has the potential to generate highly accurate geospatial analyses.

[Figure 1]

[Figure 2]

Within the RWN, footpaths were classified into one of seven categories ${ }^{5}$ which provide opportunities for more detailed analysis. It does not include informal paths indicated by worn tracks across open spaces. For comparative purposes the resolution of the RWN is compared to the road network in Figure 3. Given that it is a relatively small area surrounding people's home that seems to be most predictive of walking for transport (Learnihan et al 2011) and that the limit of the 'neighbourhood of opportunity' lies within $1000 \mathrm{~m}$ with $400 \mathrm{~m}$ being particularly influential (Boer et al 2007, Milward et al 2013), it would suggest that a network that can more accurately model the intricacies of the immediate domestic hinterland would be a better measure of walkability. Once established, this network also presents a large number of opportunities for spatial analysis to support a range of planning, policy and programme decisions for project partners ${ }^{6}$.

[Figure 3]

While it is recognised that the use of footpath networks pose unique challenges, including a lack of understanding of impedance functions for walking (lacono et al 2010), the RWN could address some of the drawbacks of using a road based network (discussed above and see Tal and Handy 2012) particularly when identifying the potential impact of new infrastructure such as greenways. In such cases the density of road intersections is clearly an inappropriate component of the Walkability Index as this measure will remain unaffected by the development of a greenway, so that the RWN, rather than the road network, should be used to record the changing connectivity characteristics of the built environment. However it is not clear whether the concept of 'Intersection Density' (used by Frank et al 2010 and IPEN) should be

\footnotetext{
${ }^{5}$ Footpaths; Road Crossings; Shared Access; Back Access; Bridges; Tracks; and Subways.

${ }^{6}$ See for example the work undertaken as part of the KESUE project: http://www.qub.ac.uk/researchcentres/KnowledgeExchangeSpatialAnalysisandHealthyUrbanEnvironments/
} 
simply transposed on to the RWN or alternatives adopted. Intersection Density appears to work effectively as a measure of connectivity for the road network because motorised traffic has a much more limited choice of route and direction of travel, with road junctions effectively representing the only opportunities for route changes. In contrast, pedestrians are at liberty to move through the built environment in a far less regulated way and subject to very different constraints and psychological influences on their navigation, with scope for a much wider variety of route choices and diversity in pedestrian behaviour. It is unclear however, whether different measures of connectivity offer improvements in reflecting pedestrian-orientated use of the built environment.

The PARC case study offers an opportunity to test these questions, as it has included a major physical activity survey which can be used to test the association between commonly used measures of connectivity against recorded levels of physical activity, noted above as being a limitation of the previous studies by Chin et al (2008) and Tal and Handy (2012). The remaining parts of this paper describe this analysis. It will describe six measures of connectivity, compare the associations between them and discuss their correlation with reported levels of physical activity.

\section{Six Measures of Connectivity}

Connectivity is essentially a measure of the 'relatedness' (Peponis et al 2008, p.881) of the built environment and is a prerequisite for pedestrian activity. It appears that the more connected a built environment, the more conducive it is to walking, independent of other neighbourhood characteristics (Berrigan et al 2010). For this reason connectivity has been used as one of the key measures in the Walkability Index, as noted above. As there is sometimes a lack of available spatial data on pedestrian networks, many researchers have used attributes of the road network as a default measure of connectivity and as explained above, deployed Intersection Density as a key indicator. Although Intersection Density appears to capture the broad characteristics of connectivity, its shortcomings have been highlighted by Stangl and Guinn (2011). They illustrate that Intersection Density is, in effect, a proxy of connectivity, rather than being a 'true' measure, in that it assumes intersections define connectivity rather than actually measuring the route distance between origins and destinations which are de facto reflections of connectivity. Furthermore, depending on the unit of analysis, areas of low intersection density could be compensated within the same analysis by a small area of high density and thus provide a misleading picture of overall connectivity. 
There is, however, no accepted standard for assessing connectivity (Stangl and Guinn, 2011). The adoption of the footpath network rather than the road network in the PARC study provides an opportunity to question whether the convention of using Intersection Density is the most appropriate measure of connectivity for walkability when using a footpath network. In order to explore this, it is useful to consider four different approaches to understanding connectivity described by Ozbil et al (2011). The first approach is to capture distinctly measurable features, such as the number of intersections or cul-de-sacs by unit area (e.g. Cevero and Radisch 1996); the second is to capture the factors that directly influence connectivity for pedestrians, including block size per area (e.g. Hess et al, 1999), Intersection Density (e.g. Lee and Moudon 2005), Link-Node Ratio (e.g. Handy et al 2003) or the average distance between intersections (op cit); the third approach includes more discriminating measures that characterise $a$ particular location on a network, such as walking catchment (i.e. Pedshed) or route directness (Stangl, 2012); and finally, Ozbil et al distinguish a fourth approach that measures accessibility based on the configuration of individual street elements such as Metric Reach (Peponis et al 2008), which draws on the work of space syntax (Hillier 1999).

A number of authors have discussed the relative merits of the different measures of connectivity (e.g. Dill, 2004, Stangl and Guinn 2011, Berrigan et al 2010), with the focus almost always being on their ability to accurately capture block and road configurations, rather than its potential impact on physical activity. In seeking to progress this analysis, it was decided to start with the 'conventional' measure of Intersection Density and compare this with 5 other measures. The first three measures are those used by Chin et al (2008) and Tal and Handy (2012) to compare the connectivity of road and pedestrian networks, namely Link-Node Ratio (LNR), Pedestrian Route Directness (PRD) and assessment of Pedsheds. These are drawn from the second and third approaches characterised by Ozbil et al (2011) and may have particular merits when measuring the characteristics of the built environment around a specific location, such as the home address of survey participants. These measures are supplemented by a further two, Metric Reach and Directional Reach which align with Ozbil et al's fourth approach and whose inclusion has been argued for by Peponis et al (2008) to reflect both advances in the field introduced through the development of space syntax and to reflect potential movement through urban networks. Each of these six measures is described below.

\section{Intersection Density}

As noted above, Intersection Density represents the number of intersections (i.e. where more than two links of a network join) per unit area. This can be based on a census unit or a defined hinterland, 
such as a $400 \mathrm{~m}$ buffer or network distance around a specific location. A higher number indicates a larger number of intersections and therefore greater connectivity. This is shown in Figure 4 . In the Belfast case the intersection density was derived for buffers calculated using the RWN to identify hinterlands of 5 minutes $(500 \mathrm{~m})$ and 10 minutes $(1000 \mathrm{~m})$ walking around participants' home addresses. The area of these hinterlands where then calculated and intersected with the junctions which had 3 or more segments.

[Figure 4]

\section{Link-Node Ratio (LNR).}

LNR is a simple ratio between the links in a network (i.e. segments between nodes) and nodes (i.e. intersections of three or more segments). The higher the ratio, the more connected the network. The sampling area can be the same as used on the Intersection Density, such as a census unit or buffer around specific locations. A perfect grid has a LNR of 2.5 (Dill 2004) and Figure 5 shows the LNR for the same examples used in Figure 4. Here the measure of connectivity has the opposite outcome compared to intersection density, as the LNR only takes into account the ratio and not the distance between the nodes, reinforcing that the choice of connectivity measure can be crucial. Chin et al (2008) defined catchments by 5, 10, 15 and 20 minutes walking distances around local schools (number unspecified) in four neighbourhoods in Perth (Australia) as a basis for their LNR calculation. In 'traditional' neighbourhoods the LNR was between 1.33-1.46 for the pedestrian network and 1.361.43 for the road network and in 'conventional' neighbourhoods, the LNR for the pedestrian network was between 1.26-1.37 and between 1.28-1.36 for the road network. In Tal and Handy's study of Davis in California (2012), the LNR for their "non-motorised network" ranged between 1.25 -1.74 and for the street network, 1.10-1.83. However, Tal and Handy did model the road-footpath intersections in a way that included fewer nodes than in our model. In the Belfast case, the LNR was derived for buffers calculated using the footpath network to identify hinterlands of 5 minutes $(500 \mathrm{~m})$ and 10 minutes $(1000 \mathrm{~m})$ walking around participants' home address. The area of these hinterlands where then used to select those links and junctions with 3 or more segments to calculate the ratio.

[Figure 5]

\section{Pedestrian Route Directness (PRD)}


The PRD falls into Ozbil et al's (2011) third approach, in that it characterises a particular location on a network by capturing the ratio of the actual route distance compared to the straight-line distance between specific origins and destinations.

$$
P R D=\frac{\text { Route distance }}{\text { Geodetic distance }}
$$

In this case however, the scale is the opposite from the other measures, so that a lower score indicates greater connectivity, with the lowest possible score being 1.00 as actual distance then equals 'as the crow flies' (Dill 2004). This overcomes some drawbacks of the LNR as it measures the actual distance travelled. The example shown in Figure 6 indicates a PRD of 1.46. Randall and Baetz (2001) provide examples of PRD calculations for two types of neighbourhoods in Hamilton, Ontario. In pre-war neighbourhoods with grid street patterns, the PRD was found to be between 1.4-1.5 and for post-war suburbs with curvilinear streets and cul-de-sacs, the PRD was between 1.6-1.9, although it is unclear what type of destinations were used for this analysis. In their research, Chin et al (2008) used local schools in four neighbourhoods (number unspecified) in Perth (Australia) as the origin to all 'destinations' (unspecified) within 5, 10, 15 and 20 minutes walking distances. In 'traditional' neighbourhoods the PRD was between 1.31-1.39 for the pedestrian network and 1.44-1.60 for the road network and in 'conventional' neighbourhoods, the PRD for the pedestrian network was between 1.35-1.44 and between 1.63-1.92 for the road network. The Belfast case used the distances from homes of the participants' to the gates of the nearest municipally-maintained park. This analysis was calculated using the using the 'Nearest Facility' function within ArcGIS.

[Figure 6]

\section{Pedshed}

Pedsheds (walkable catchments) also fall into Ozbil et al's (2011) third approach and measure the area around specific points that are accessible using the footpath or road network as a percentage of the area defined by a geodetic buffer around the same point, as shown in Figure 7. A higher percentage indicates greater connectivity. In their analysis in Australia, Chin et al (2008) found that Pedshed 
values for 'traditional' neighbourhoods were between 55\% and 63\% for the pedestrian network and $48 \%$ and $56 \%$ for the road network and in 'conventional' neighbourhoods the Pedsheds were between $49 \%$ and $57 \%$ for the pedestrian network and $24 \%$ and $47 \%$ for the road network. In the Belfast case, Pedsheds were calculated for the addresses of each participant for 5 minutes $(500 \mathrm{~m})$ and 10 minutes $(1000 \mathrm{~m})$ walking distances, using the footpath network and a 'crow flies' buffer of the same distance

$$
\text { Pedshed }=\frac{\text { Area acessible by walking distance using footpath network }}{\text { Area defined by geodetic buffer }} \times 100
$$

[Figure 7]

\section{Metric Reach}

The Metric Reach is the network length that can be covered walking in all possible directions from a point of origin for a certain distance threshold, essentially a means of measuring the density of available footpaths. The greater the Metric Reach, the higher the connectivity of the built environment. This falls into Ozbil et al's fourth approach and in some ways is similar to Pedsheds, except it measures connectivity in terms of the length of accessible network and not as a percentage of "as the crow flies" distance. Peponis et al (2008) formally define the "Metric Reach $R_{v}\left(P_{i}, \mu\right)$ of a point $P_{i}$ according to a metric threshold $\mu$ as the length of the road segments and tractions of road segments covered by the union of all paths for which $s \leq \mu$ " (p. 883), with no line segment counted twice. This is shown in Figure 8.

$$
\text { Metric Reach }=R_{v}\left(P_{i}, \mu\right)
$$

The Metric Reach captures the density of networks and the density of intersections. It can include fractions of road segments and not just complete segments, although we have included only entire footpath elements in our own analysis. Peponis et al applied their analysis to roads only and not to a footpath network, finding average values in the Atlanta, Georgia for a 1 mile threshold to be between 6.51 and 39.78 miles. Peponis et al (2008) note that one of the advantages of Metric Reach is that it can be used for both large areas, or down to quite small areas, while measures such as intersection density or LNR are aggregate measures of wider areas. This may therefore have greater accuracy when looking at the environment immediately around people's homes. Metric Reach was calculated for the 
address of each participant for 5 minutes $(500 \mathrm{~m})$ and 10 minutes $(1000 \mathrm{~m})$ walking distances, by using the 'Service Area' function in ArcGIS to create a hinterland around the addresses and then intersecting the footpath network to measure the total network distance covered within that hinterland.

[Figure 8]

\section{Directional Reach}

Like Metric Reach, Directional Reach is a measurement of the network length that can be covered walking in every direction at certain time thresholds, with a further condition based on the number of changes in direction. Peponis et al (2008), draw on insights from space syntax (Hillier 1999) to suggest that connectivity should be measured not just in terms of distance, but should also take into account the way individuals interpret space. They point to the evidence on spatial cognition that shows that accessibility measured by directional changes can be used to predict pedestrian movements through the built environment, suggesting 'directional reach' as a measure of connectivity. Peponis et al $(2008$, p. 893$)$ provide the following definition 'Directional Reach $R_{u}\left(P_{i}, \delta\right.$, $\propto, r)$ of a point $P_{i}$, according to a directional threshold $\delta$ as the aggregate length of the road segments and fractions of road segments that are no more than two direction changes away, subject to a direction change threshold angle $\propto$ and a very small line segment threshold set to a fraction $r$ of the average road segment length'. This also falls into Ozbil et al's (2011) fourth approach and likewise, the greater the Directional Reach, the higher the connectivity of an area. Directional Reach is sensitive to the shape and alignment of streets, not just their density, and can be used in large and small scale research, Ozbil et al (2011). Peponis et al's analysis of Directional Reach using the road network found average values in Atlanta, Georgia for a 1 mile threshold with no more than two changes of direction of more than 20 degrees, to be between 3.22 and 9.50 miles. In our analysis we have also employed a direction change threshold angle $(\propto)=20^{\circ}$. Directional Reach was calculated for the address of each participant for 5 minutes $(500 \mathrm{~m})$ and 10 minutes $(1000 \mathrm{~m})$ walking distances, by using the 'Service Area' function in ArcGIS to create a hinterland around the addresses and then intersecting the footpath network to measure the total network distance covered within that hinterland. This is similar to the calculation of metric reach however the parameters were limited two a maximum of two turns or a turn which is $20^{\circ}$ of less

$$
\text { Directional Reach }=R_{u}\left(P_{i}, \delta, \propto, r\right)
$$


[Figure 9]

These measures represent different aspects of connectivity and appear to be appropriate to different spatial scales of analysis. Thus, Intersection Density and LNR aim to provide a broad indication of the connectivity characteristics of an area, in this case centred on our participants' home address. The Pedshed and PRD seek to measure directly how easily participants can reach specific destinations around their home and for the PRD the connection to a particular specific type of land use, in this case a park. The final two measures, Metric Reach and Directional Reach seek to reflect the density of the footpath network around participants home and therefore would be expected to relate to the opportunities for maximising route choices and direction, although it is not clear whether this in itself has a significant link to physical activity. Therefore each of these different measures of connectivity may reflect subtle differences in the way in which the built environment influences physical activity.

\section{Comparing connectivity measures}

The PARC study included a survey of local residents (Feb 2010 - Jan 2011) ${ }^{7}$ that explored, inter alia, their levels of physical activity prior to the Greenway being constructed. The same survey will be repeated in Feb 2016 - Jan 2017 following once the Greenway is completed. A representative stratified random sample of 1,209 adults completed a household interview (households were randomly selected through the Postcode Address File) and a resident (+16 years) was randomly selected for interview. Of the 1209 participants, 814 lived within $1000 \mathrm{~m}$ of the Greenway and it is this sub-group that has been used for analysis here. Table 1 provides the demographic profile of the sample group.

\section{[Table 1]}

Table 2 compares the attributes of the connectivity measures from the PARC study area. For the analysis we reversed the PRD measure by dividing network distance/Euclidian distance so that the direction of the measure was in line with the other connectivity measures. While comparison is difficult due to the different units used, it does offer a number of useful comparisons of how they describe the urban form of the inner core of a de-industrialized European city. If we compare the scores for the three measures in this study that are directly comparable to the data provided in Chin et al (2008), we find that the

\footnotetext{
${ }^{7}$ This was approved by the Office for Research Ethics Committees (ORECNI), Northern Ireland (ref 09/NIR02/66).
} 
Belfast area appears to be less well connected than the area studied in Perth, Australia. For example, while the 10 minute Pedshed in 'conventional' and 'traditional' neighborhoods in Perth were 56\% and $59 \%$ respectively, it is $44 \%$ in Belfast. The LNR shows even great disparity, with the 10 minute buffer in Perth being 1.35 and 1.41 for 'conventional' and 'traditional' neighborhoods respectively and in Belfast it was only 0.55. As noted by Tal and Handy (2012) the particular way the network is represented can have a substantial impact on the measures of connectivity, with road crossings in the RWN increasing the number of nodes (see Figure 2). However, the PRD in Perth was between 1.42-1.44 yet in Belfast it was more comparable at 1.5. This provides an interesting comparison both in how very different built environments compare against each of these measures and in the variety of the comparisons. While LNR shows vast differences (potentially reflecting a greater variety of built form in Belfast), the PRD is very similar. Surprisingly, Perth appears to be better connected than Belfast, despite Australia being conventionally regarded as having more sprawling, car-orientated cities compared to those found in Europe.

[Table 2]

Table 3 correlates the connectivity measures with each other, illustrating the relationships we would expect given the attributes of each measure. There is clearly a relationship between each of the measures which are broadly capturing the same features of the built environment, as noted by Randall and Baetz (2001) and Dill (2004). However, the greatest correlation appears to be between 10 min Metric Reach and the 10 minute Intersection Density, perhaps reflecting the fact that both represent different measures of the density of footpaths, with Metric Reach measuring the density of footpath length, and Intersection Density the junctions of different paths. Interestingly, there is a strong correlation between Metric Reach and Pedshed (at 5 and 10) reflecting how they also both rely on a density of footpaths, but only a weak correlation between Pedshed and Intersection Density. Despite the similarity in how LNR and Intersection Density are calculated, their correlation is greater at 5 min hinterlands than at $10 \mathrm{~min}$ hinterlands, potentially highlighting a high average length of footpath elements. The weakest correlations arise from the relationships between Directional Reach and other measures, reflecting the fact that this incorporates changes in direction along single elements of the network. The weakest of these is the correlation with Intersection Density and the strongest correlation, unsurprisingly, is with Metric Reach. 
[Table 3]

Table 4 shows the results when the connectivity measures are compared with self-reported physical activity data ${ }^{8}$, collected using the Global Physical Activity Questionnaire (GPAQ) (Bull et al, 2009), as part of the survey described above. Data were collected with regard to frequency, duration and intensity of physical activities in work, active travel, and recreation domains during the previous 7 days. Minutes of active travel per week were calculated using the validated method whereby average number of days per week and minutes per day spent in some mode of active travel (e.g. walking or cycling) were aggregated to derive a summary variable (Bull et al, 2009). Descriptive statistics were calculated ${ }^{9}$ using frequencies for categorical variables and mean \pm SD for continuous variables. As minutes of active travel was nonnormally distributed, it is reported using median and interquartile range. Spearman's rank correlation was used to investigate the relationship between minutes of active travel per week with each connectivity measure.

[Table 4]

\section{Discussion: Connectivity, Physical Activity and the Walkability Index}

This analysis provides insights in a number of areas. First, because each measure informs us about slightly different constructs, it helps clarify the relationship between connectivity measures and how they relate to active travel. Second, it sheds light on the most suitable connectivity measures to incorporate when revising the Walkability Index of the built environment based on a footpath network. We shall discuss each of these issues in turn.

Table 4 shows that connectivity is, at best, only weakly associated with time spent in active travel by those living in the PARC study area and therefore as a sole measure of the built environment, none is ideal in reflecting the complexity of pedestrian behaviour (noting the qualifications in footnote 8 below). Indeed this is why connectivity is usually combined with other attributes of the built environment (such as land

\footnotetext{
${ }^{8}$ We recognise that there are a range of factors that may influence active travel behaviour beyond the built environment and that the influence of the built environment beyond the local area discussed here may also have an effect. However, we have adopted the approach to assessing built environment effects as recommended by is the International Physical Activity and Environment Network, a consortium of international experts see http://www.ipenproject.org/.

${ }^{9}$ Thus used SPSS ver.20.0 Software for Windows (SPPS Inc, Chicago, USA).
} 
use mix) in a Walkability Index. However, as an important component of the Walkability Index, connectivity deserves a close examination and while Table 3 suggests a broad correlation between the connectivity measures themselves, Table 4 highlights their correlation with recorded levels of physical activity. Our analysis confirms that Intersection Density appears to offer the best measure of connectivity related to physical activity when using the footpath network. Metric Reach is also a good measure and may be considered appropriate in some circumstances (such as part of a combined measure of proximity and connectivity) and deserves further investigation. While confirming previous views of the Walkability Index (e.g. Frank 2010 et al), this finding appears to conflict with the conclusions of Stangl and Guinn (2011) and Stangl (2012), who suggested that PRD was a more effective measure, at least for the purposes of measuring urban morphology (rather than physical activity). Table 4 shows that in this sample, the PRD has one of the weakest correlations with physical activity. Similarly, while Directional Reach appears to offer potential by incorporating aspects of the space syntax which have predicted movement through the built environment, it appears to be a weak measure in the context of this study. One possible explanation is that because the nature of the built environment in East Belfast, the area covered by Directional Reach is very small and does not provides an adequate statistical sample. This suggests it is not very effective in capturing active travel in the type of built environment represented by the study area - a dense, deindustrialised, inner city, which has evolved organically and where 'twists and turns' are the norm, rather than in more highly planned environments. It is possible that a change in the parameters of the Directional Reach (i.e. a decay of more than two changes in direction or using a higher threshold degree for changing direction) would produce greater correlation with physical activity, but this has not been explored in the context of this study.

Furthermore, while this paper has extended the insights of Chin et al (2008) and Tal and Handy (2012) in exploring the use of a footpath network rather than a road network, the three measures they used (Pedshed, PRD and LNR), perform particularity poorly in this analysis. The performance of PRD may be dependent on the specific destination chosen as the basis for analysis (in this case local parks, while local shops or public transport may give different results). Indeed while PRD may have a role in evaluating the role of specific services and land uses on physical activity, it does not appear suitable as a generalised indicator for connectivity as a component of a Walkability Index. The poor correlation of LNR is explained by the fact that you can get very different scores for LNR and Intersections Density for the same area, depending on the characteristics of the network, as shown in Figures 4 and 5. We note however, that this may have also been influenced by the number of nodes mapped as a way of modelling the road crossings 
(see Figure 2 and Tal and Handy, 2012). Table 3 shows that in the case of the PARC study area, and using the RWN, LNR is poorly correlated with Intersection Density.

Finally, it is useful to highlight that of the measures that can be derived for 5 and 10 minute hinterlands (i.e. not Directional Reach and PRD), there is a greater correlation over a 10 minute hinterland than for the 5 minute hinterland. This may be a reflection of a number of factors related to both the way these measures capture the features of the built environment (for example LNR being more appropriate for larger areas) and the spatial unit that may have the greatest influence on physical activity. While Learnihan et al 2011 have suggested that a 15 minute hinterland around someone's residential address is far more predictive of active travel at suburb or census collection district; we are still unclear about the appropriateness of a more accurate measure of the area of influence (Clark and Scott 2014). Our findings appear to suggest that 10 minute hinterlands are more influential than 5 minute hinterlands, but no further upper limit has been tested here. As with other research that deploys GPAQ as the source or physical activity data, there is also the potential impact of physical activity taken outside of the domesticcentred zone of influence.

Therefore, while we are cognisant of the limitations of this relatively small sample, this analysis suggests that when adopting a footpath network for walkability analysis, it is appropriate to continue to use Intersection Density, although further investigation of the advantages of substituting this with Metric Reach are worthy of further analysis. It has also raised important questions over the scale of analysis and the careful choice of the parameters used to calculate other measures of connectivity, such as Directional Reach.

\section{Conclusion}

This paper has explored some of the implications of replacing a road network with a footpath network, which may be appropriate in certain analyses and practice-based applications. While the limited availability of footpath network data has meant the road network is more commonly used to assess the walkability of the built environment - and provides good results for many types of analysis - there are many types of application, particularly related to the viability or impact of non-motorised infrastructure, or in certain types of built environment, where this may have decreasing accuracy and relevance. In these contexts, a case can be made for basing assessments of walkability on footpath networks, leading to the question of whether the components conventionally used as part of the Walkability Index should remain 
the same. Connectivity is related directly to network characteristics and often double-weighted (e.g. Frank et al 2010). This was the starting point for our analysis, to provide confidence that we were using the most appropriate measure of connectivity in our adoption of the footpath network. Although no previous study has evaluated this using actual measures of physical activity, the only other assessments of the connectivity characteristics of a footpath network (Chin et al 2008, Tal and Handy 2012) suggested that there were significant differences compared to the road network (or at least in the case of Perth and Davis), which could result in potentially major discrepancies in results. They also suggested that measures of connectivity, other than the conventionally use Intersection Density, such as Pedshed, LNR and PRD should be deployed. This study does not support the routine use of these measures when assessing the relationship between the built environment and physical activity, with our analysis indicating that these measures have a weaker correlation with levels of physical activity than Intersection Density or Metric Reach. On this basis, we suggest that where the footpath network is used, this should be represented in a Walkability Index in the form of Intersection Density, even when focussing on relatively small areas.

While the limitations of a single case study should be considered, this also raises a number of questions for walkability research. First, it highlights that the notion of "connectivity" itself has a number of attributes, with some of these having greater relevance to actual pedestrian behaviour than others. In the case discussed here, it appears that Intersection Density has a closer relationship than, say PRD or Directional Reach, suggesting that it is the general connectivity of an area that maximises accessibility of all aspects of a neighbourhood, rather than very specific locational features or more cognition-related issues that has a greater influence on overall levels of physical activity. Indeed, each of the measures of connectivity subtlety captures slightly different aspects of the broader concept of 'connectivity'. Perhaps the implication of this is that we should think about a more nuanced concept of connectivity when thinking about walkability (perhaps "active travel accessibility"?), to distinguish it from other approaches, such as those focusing on urban morphology per se or pedestrian movement. It also prompts consideration of when it is appropriate to adopt a footpath network as the basis for analysis rather than the road network and the benefits that may arise from using the former. This calls for an examination of whether these relationships make any difference when used as a component of a Walkability Index based on footpath network and whether an Index based on footpath network is better associated with physical activity compared to one based on the road network. Related to this, our analysis suggests there is a need to orientate walkability research to the specific needs of practitioners. Indeed, one of the inhibiting factors in translating the findings of walkability research into practice is the continued dominance of car-based 
data and modelling, which tends to reproduce car-based planning solutions (Weinberger and Sweet 2012). The whole notion of pedestrian planning is poorly developed and in his review of such practice, Stagl (2011) found that, according to a survey of US planners, connectivity was seen to be the most important environmental attribute for promoting walking, yet needed to be integrated into practice in a far more meaningful way. Stagl (2011) suggested that despite its recognised importance, the concept of connectivity faced a number of barriers to its practical application, particularly the lack of a universally accepted quantitative measure and the need for more meaningful comparative studies, key factors addressed by this paper. 


\section{REFERENCES}

Allender, S, Fosterm C, Scarborough, P and Rayner, M (2009) 'The burden of physical activity-related ill health in the UK' Journal of Epidemiology and Community Health 61 (4) 344-348

Bauman, AE, Reis, RS, Sallis, JF, Wells, JC, Loos RJ, and Martin BW (2012) "Correlates of physical activity: why are some people physically active and others not?" The Lancet, 380 (9838) 258-271.

Berrigan, D, Pickle, LW and Dill, J (2010) "Associations between street connectivity and active transportation" International Journal of Health Geographics, 9(1) 20-38.

Boer, R., Zheng, Y., Overton, A., Ridgeway, G.K. and Cohen, D. A. (2007) 'Neighbourhood design and walking trips in ten U.S. metropolitan areas, American Journal of Preventive Medicine, 32, 298-304.

Brownson, RC, Hoehner CM, Day K, Forsyth A and Sallis, JF (2009) "Measuring the Built Environment for Physical Activity: State of the Science" American Journal of Preventative Medicine 36 (4S), S99-S123.

Bull FC, Maslin TS, Armstrong T (2009) "Global Physical Activity Questionnaire (GPAQ): nine country reliability and validity study" Journal of Physical Activity and Health 6(6) 790-804.

Bull F, Giles-Corti B and Wood L (2010) "Active landscapes: the methodological challenges in developing the evidence on urban environmental and physical activity" in Innovative approaches to researching landscape and health, Eds Ward Thompson C, Aspinall P and Bell S (Routledge, London) pp 97-120.

Butland B, Jebb S, Kopelman P, McPherson K, Thomas S, Mardell J, Parry V (2007) Foresight Tackling Obesities: Future Choices - Project Report, Government Office for Science, London.

Cerin E, Saelens, BE, Sallis JF and Frank LD (2006) “Neighborhood Environment Walkability Scale: validity and development of a short form" Medicine and Science in Sports and Exercise 38(9) 1682-1691.

Cervero R, and Radisch C (1996) "Travel choices in pedestrian versus automobile oriented neighborhoods" Transport Policy 3(3) 127-141.

Chin, GKW, Van Niel, KP, Giles-Corti, B, Knuiman, M (2008) "Accessibility and connectivity in physical activity studies: The impact of missing pedestrian data" Preventive Medicine 46(1) 41-45.

Clark, A. and Scott, D. (2014) "Understanding the Impact of the Modifiable Areal Unit Problem on the Relationship between Active Travel and the Built Environment" Urban Studies 51(2) 284-299.

Dill J (2004) "Measuring network connectivity for bicycling and walking" Paper submitted to $89^{\text {th }}$ Transport Research Board Annual Meeting, Williamsburg, Virginia. Available at: http://reconnectingamerica.org/assets/Uploads/TRB2004-001550.pdf Last accessed 01/07/13.

Ding D, Gebel K (2012) "Built environment, physical activity, and obesity: what have we learned from reviewing the literature?" Health Place 18(1) 100-5. 
Frank LD, Sallis, JF, Saelens BE, Leary L, Cain K, Conway, TL, and Hess PM (2010) "The development of a walkability index; application to the Neighbourhood Quality of Life Study" British Journal of Sports Medicine, 44(13) 924-933.

Frizelle B G, Evenson K R, Rodriguez D A, and Laraia B A (2009) 'The importance of accurate road data for spatial applications: Customizing a road network'. International Journal of Geographics 8: 24

Giles-Corti B, Bull F, Knuiman M, McCormack G, Van Niel K, Timperio A, Christian H, Foster S, Divitini M, Middleton N and Boruff B (2013) "The influence of urban design on neighbourhood walking following residential relocation: longitudinal results from the RESIDE study" Social Science and Medicine, 77, 20-30.

Grasser G, Van Dyck D, Titze S, Stronegger W. (2013) Objectively measured walkability and active transport and weight-related outcomes in adults: a systematic review" "International Journal of Public Health 58(4) 615-25.

Guthman J (2013) "Too much food and too little sidewalk? Problemitizing the obesogenic environment thesis" Environment and Planning A 45 142-158.

Hajna S, Dasgupta K, Halparin M and Ross NA (2013) "Neighbourhood Walkability: Field Validation of Geographic Information System Measures" American Journal of Preventive Medicine, 44(6), e51-e55

Hamer M, Chida Y (2008) Walking and primary prevention: a meta-analysis of prospective cohort studies, British Journal of Sports Medicine, 42 238-243

Handy S, Paterson, RG and Butler, K (2003) Planning for street connectivity: getting from here to there (No. PAS Report No. 515), American Planning Association, Chicago.

Hein et al 2008' and the reference added as 'Hein, J. R., Evans, J., \& Jones, P. (2008). Mobile methodologies: theory, technology and practice. Geography Compass, 2(5),

Hess PM, Moudon AV, Snyder M and Stanilov K (1999) "Site design and pedestrian travel" Transportation Research Record: Journal of the Transportation Research Board 1674(1) 9-19.

Hillier B (1999) "The hidden geometry of deformed grids: or, why space syntax works, when it looks as though it shouldn't" Environment and Planning B: Planning and Design 26, 126-191.

lacono M, Krizek Kand El-Geneid, A. (2010). "Measuring non-motorized accessibility: issues, alternatives, and execution" Journal of Transport Geography, 18(1) 133-140.

Kohl 3rd HW, Craig CL, Lambert EV, Inoue S, Alkandari JR, Leetongin G, Kahlmeier S, for the Lancet Physical Activity Series Working Group (2012) "The pandemic of physical inactivity: global action for public health" Lancet 380:294-305.

Koohsari, M.J., Sugiyama, T., Lamb, K.E., Villanueva, K. and Owen, N. (2014) Street Connectivity and walking for transport: role of neighbourhood destinations, Preventative Medicine, 66, 118-122

Learnihan V, Van Niel KP, Giles-Corti B. and Knuman M. (2011) "Effect of Scale on the Links between Walking and Urban Design" Geographical Research 49 (2) 183-191. 
Lee I-M, Shiroma EJ, Lobelo F, Puska P, Blair SN, Katzmarzyk PT for the Lancet Physical Activity Series Working Group (2012) "Effect of physical inactivity on major non-communicable diseases worldwide: an analysis of burden of disease and life expectancy" Lancet 380 219-29.

Lee C and Moudon, AV (2006) "The 3Ds+ R: Quantifying land use and urban form correlates of walking" Transportation Research Part D: Transport and Environment, 11(3) 204-215.

Leslie E, Coffee N., Frank L, Owen N, Bauman A and Hugo, G (2007) "Walkability of local communities: using geographic information systems to objectively assess relevant environmental attributes" Health and Place 13(1) 111-122.

Lin L and Moudon AV (2010) "Objective versus subjective measures of the built environment, which are most effective in capturing associations with walking?" Health and Place 6 339-348.

Millward H, Spinney J and Scott D(2013) "Active-transport walking behaviour: destinations, durations, distances" Journal of Transport Geography 28 101-110.

Murphy MH, Nevill AM, Murtagh EM and Holder RL (2007) "The effect of walking on fitness, fatness and resting blood pressure: a meta-analysis of randomised, controlled trials" Preventative Medicine, 44 377385.

National Institute for Clinical Excellence (NICE) (2012) Walking and cycling: local measures to promote walking and cycling as forms of travel or recreation, guidance.nice.org.uk/ph41

Ozbil, A, Peponis, J and Stone, B (2011) "Understanding the link between street connectivity, land use and pedestrian flows" Urban Design International 16(2) 125-141.

Owen N, Humpel N, Leslie E, Bauman A and Sallis J (2004) "Understanding environmental influences on walking; review and research agenda" American Journal of Preventative Medicine, 24(1) 67-76.

Peponis J, Bafna S and Zhang Z (2008) "The connectivity of streets: reach and directional distance" Environment and Planning B: Planning \& Design 35(5) 881-902.

Randall TA, and Baetz BW (2001) "Evaluating pedestrian connectivity for suburban sustainability" Journal of Urban Planning and Development 127(1) 1-15.

Sallis JF, Floyd, MF, Rodríguez DA and Saelens BE (2012) "Role of built environments in physical activity, obesity, and cardiovascular disease" Circulation 125(5) 729-737

Schilling JM, Giles-Corti B and Sallis JF (2009) "Connecting active living research and public policy: transdisciplinary research and policy interventions to increase physical activity" Journal of Public Health Policy 30 S1-S15.

Southworth M (2005) "Designing the walkable city" Journal of Urban Planning and Development, 131(4) 246-257. 
Stangl P (2011) "The US pedestrian plan: Linking practice and research" Planning Practice and Research, 26(3) 289-305.

Stangl P (2012) "The pedestrian route directness test: A new level-of-service model" Urban Design International 17(3) 228-238.

Stangl P and Guinn JM (2011) "Neighborhood design, connectivity assessment and obstruction" Urban Design International 16(4) 285-296.

Tal, G., \& Handy, S. (2012). Measuring nonmotorized accessibility and connectivity in a robust pedestrian network. Transportation Research Record: Journal of the Transportation Research Board, 2299(1), 48-

56.

Tully MA, Hunter RF, McAneney H, Cupples ME, Donnelly M, Ellis G, Hutchinson G, Prior L, Stevenson M, Kee F (2013) "Physical Activity and the Rejuvenation of Connswater (PARC study): protocol for a natural experiment investigating the impact of urban regeneration on public health" BMC Public Health 13(1) 19

Van Lenthe, FJ and Kamphuis, CBM (2011) Mismatched perceptions of neighbourhood walkability: Need for interventions?, Health and Place, 17 (6) 1294-5

Villanueva K, Pereira G, Knuiman M, Bull F, Wood L, Christian H., Foster S, Boruff BJ, Beesley B, Hickey S, Joyce S, Nathan A, Saarloos D, and Giles-Corti, B (2013) "The impact of the built environment on health across the life course: design of a cross-sectional data linkage study" BMJ Open, 3 e002482.

Weinberger, R and Sweet MN (2012) "Integrating Walkability into Planning Practice." Transportation Research Record: Journal of the Transportation Research Board 2322(1) 20-30. 
Reproduced from Land and Property Services data with the permission of the Controller of Her Majesty's Stationary Office, (C Crown Copyright and database rights MOU 2013

Figure 1: Map of the PARC study area in context of Belfast

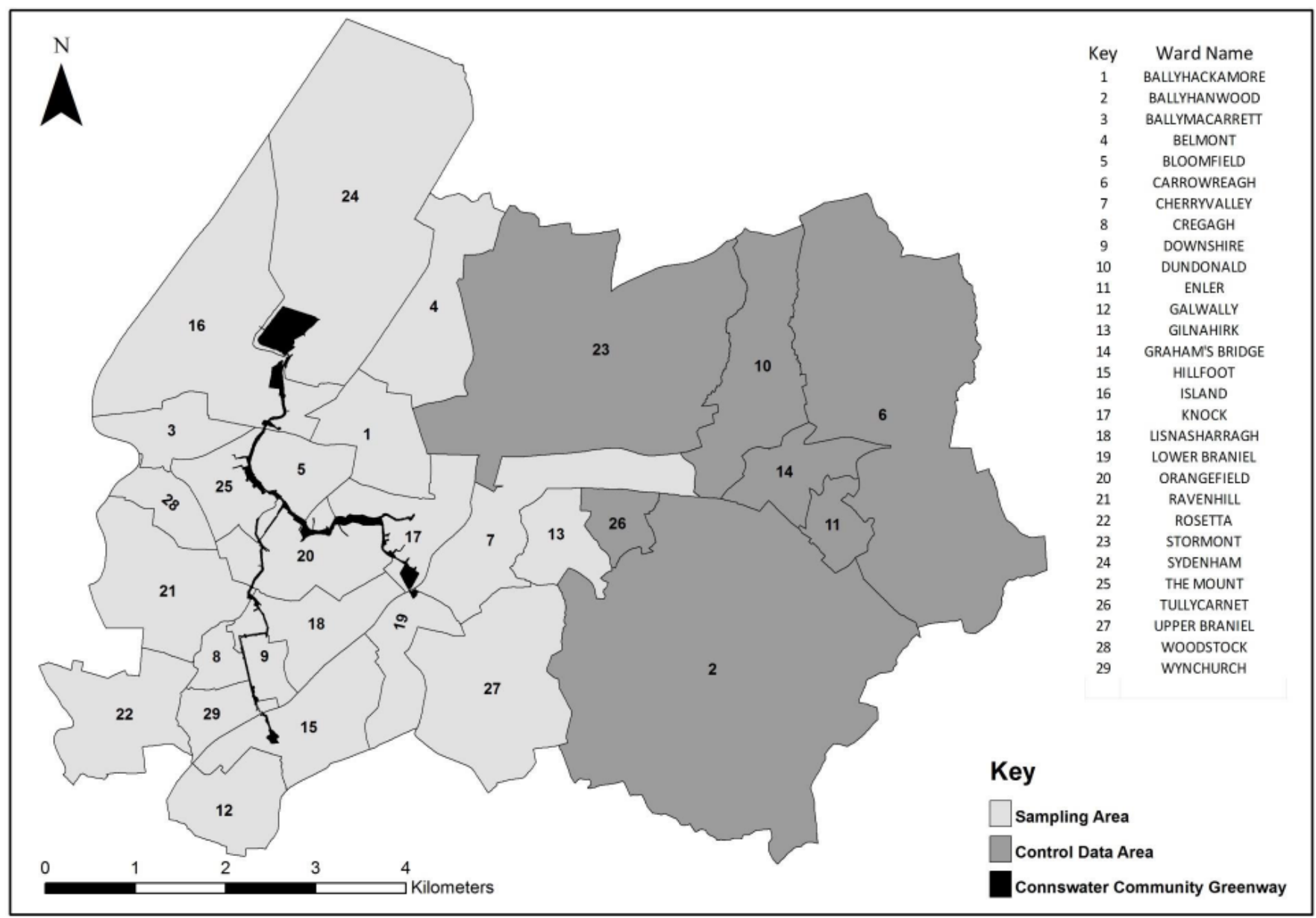


Figure 2: The Real Walkable Network with detail showing arrangement for nodes at road crossings.
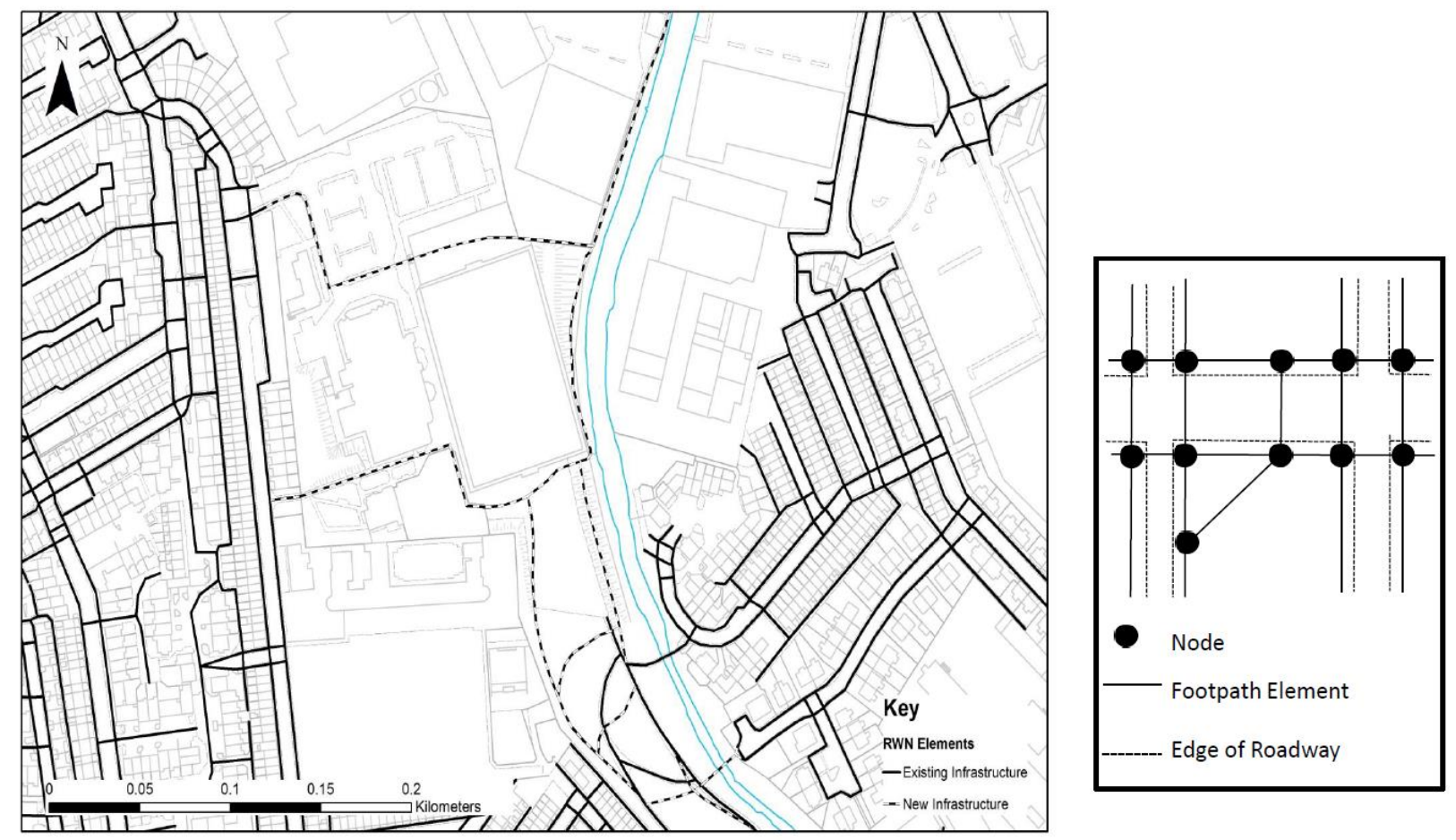

Reproduced from Land and Property Services data with the permission of the Controller of Her Majesty's Stationary Office, (C) Crown Copyright and database rights MOU 2013 
Reproduced from Land and Property Services data with the permission of the Controller of Her Majesty's Stationary Office, (C) Crown Copyright and database rights MOU 2013

Figure 3: Resolution of the Real Walkable Network RWN) v Road Network

Real Walkable Network

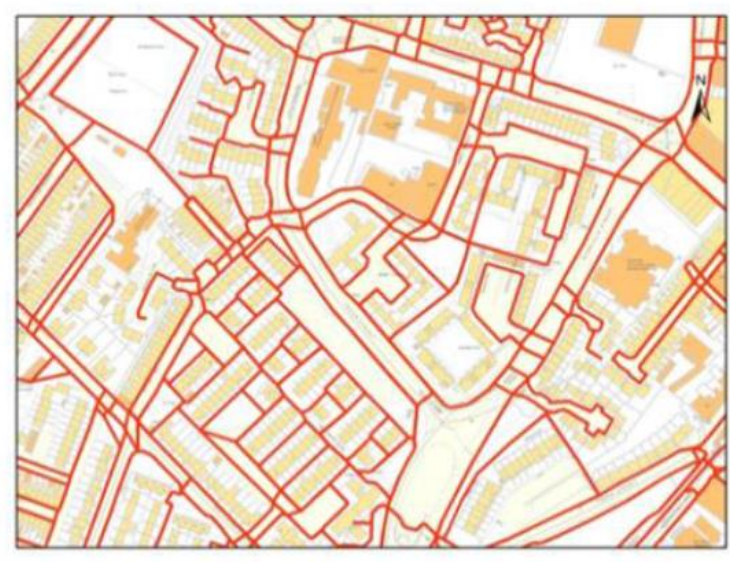

\section{Road Network}

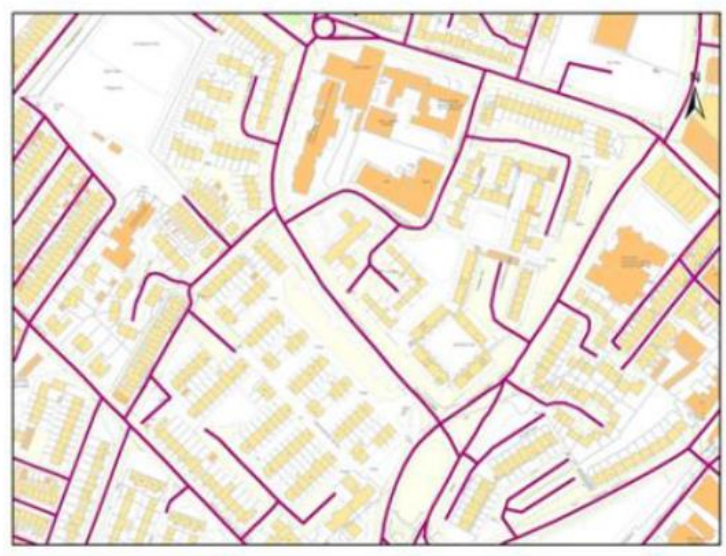

Figure 4: Intersection Density

Intersection/node

Network Segment (i.e. road or footpath segment)

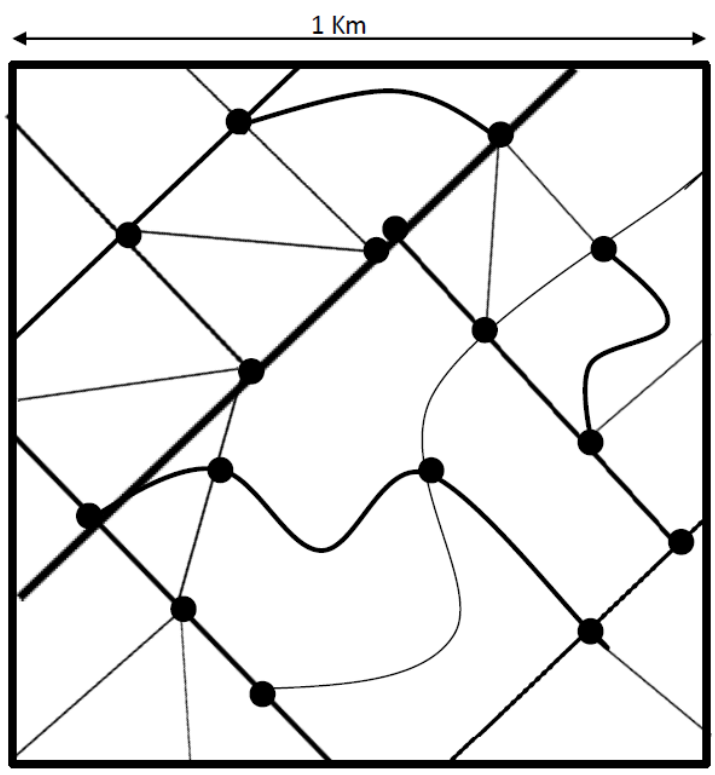

Network A: 16 intersections per $\mathrm{km}^{2}$ : Higher Connectivity

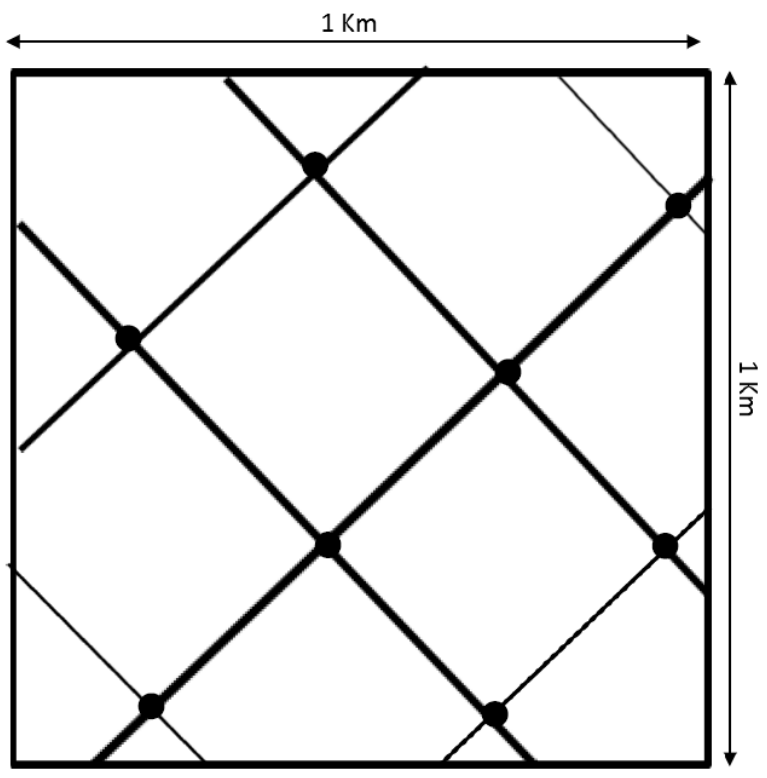

Network B: 8 intersections per $\mathrm{km}^{2}$ : Lower Connectivity 
Intersection/node

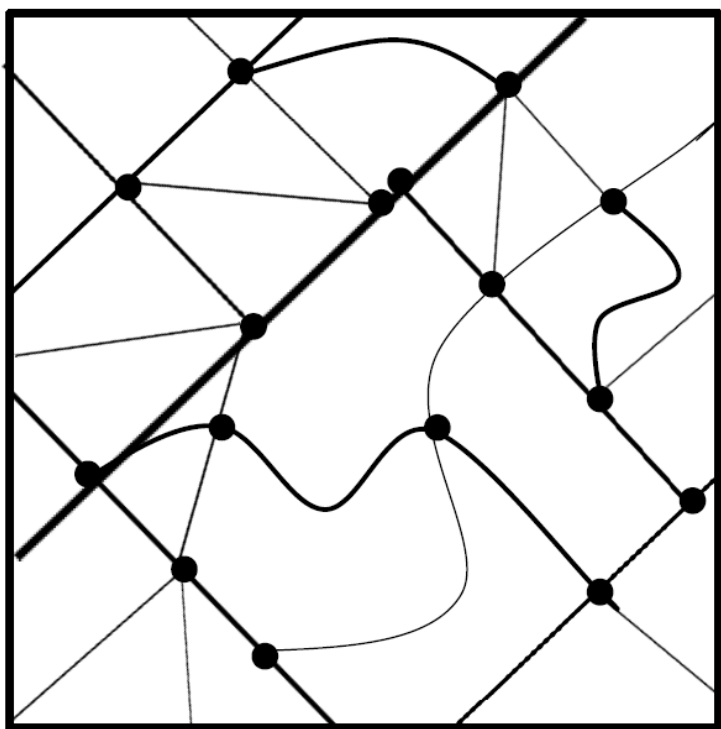

Network A: Link-Node Ratio of

$41: 16=2.56$

Lower Connectivity
Network Segment (i.e. road or footpath segment)

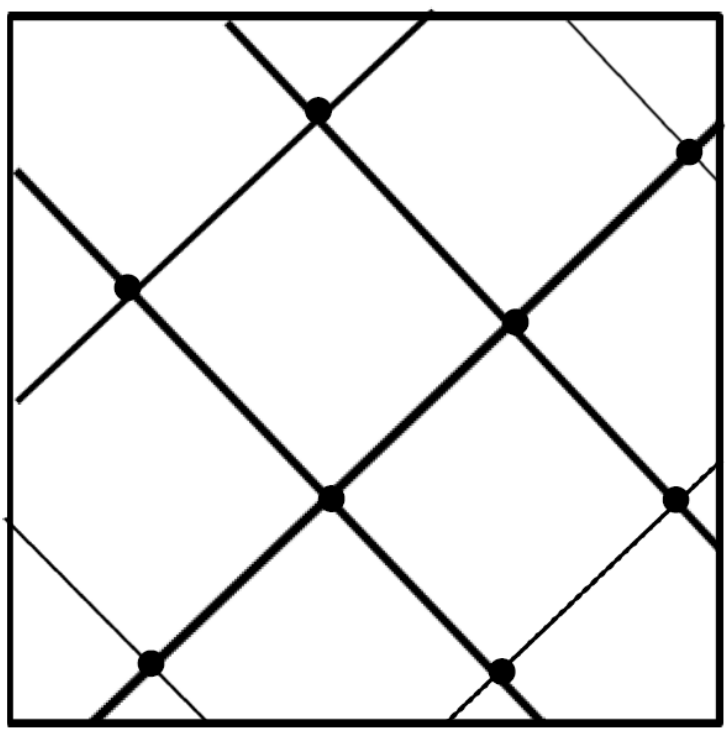

Network B: Link-Node Ratio of

$23: 8=2.88$

Higher Connectivity

Figure 6: Pedestrian Route Directness

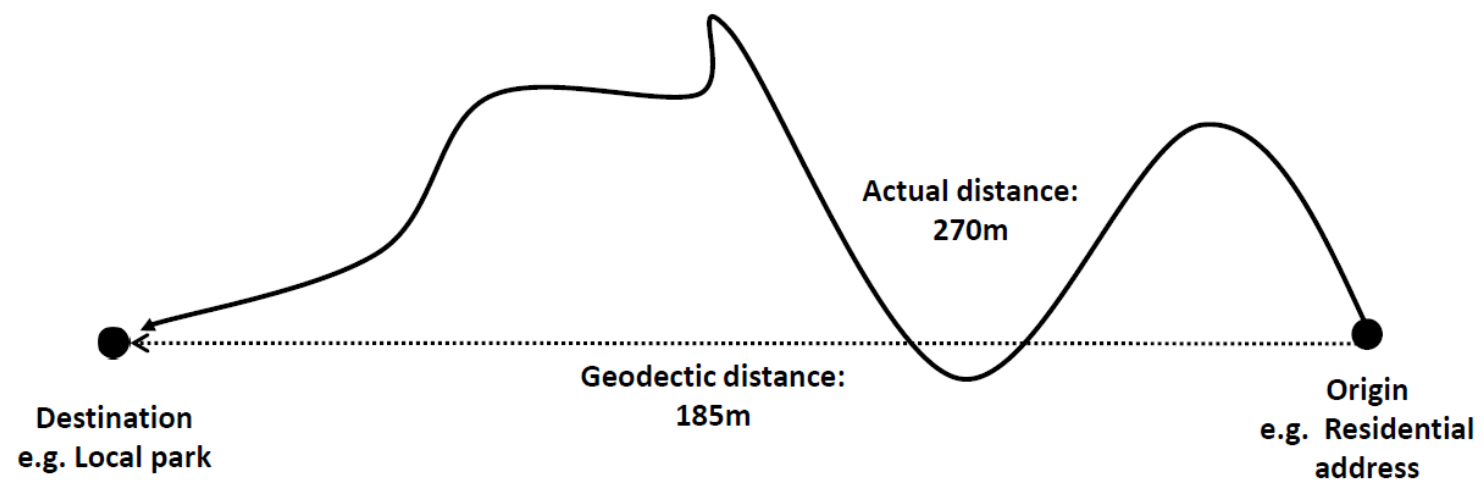

$P R D=270 / 185=1.46$ 


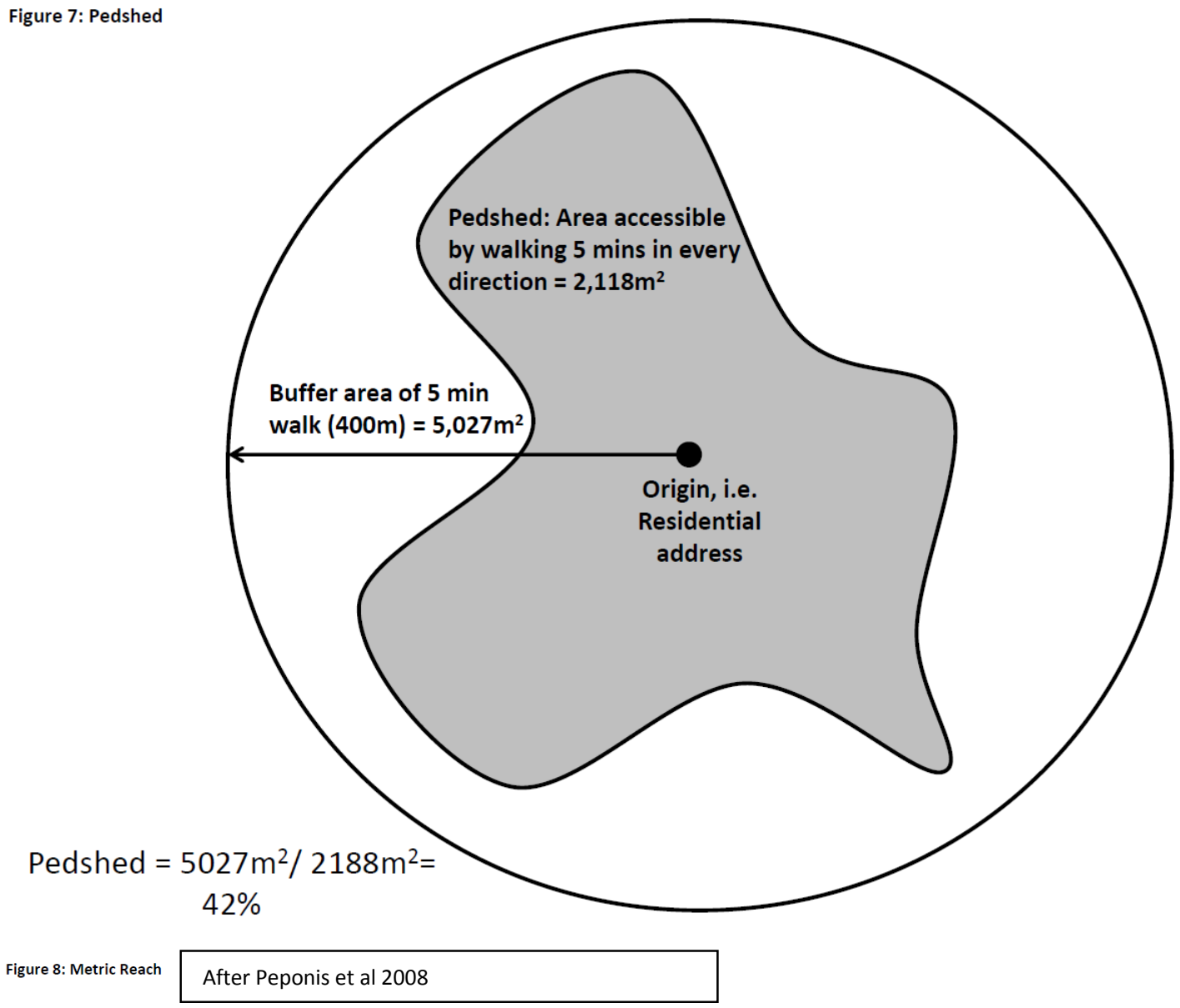

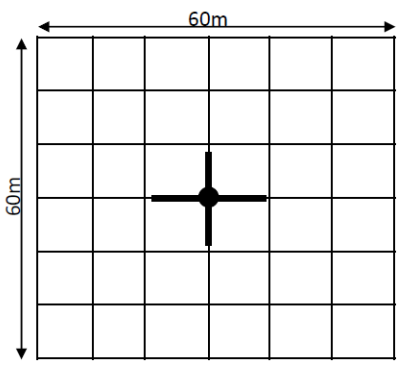

Metric Reach $=260 \mathrm{~m}$

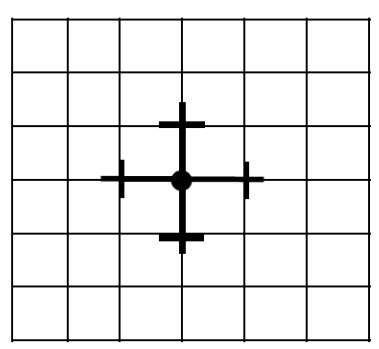

Metric Reach $=600 \mathrm{~m}$

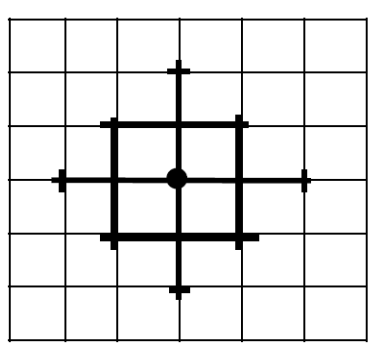

Metric Reach $=1300 \mathrm{~m}$

Distance threshold

After Peponis et al, 2008 


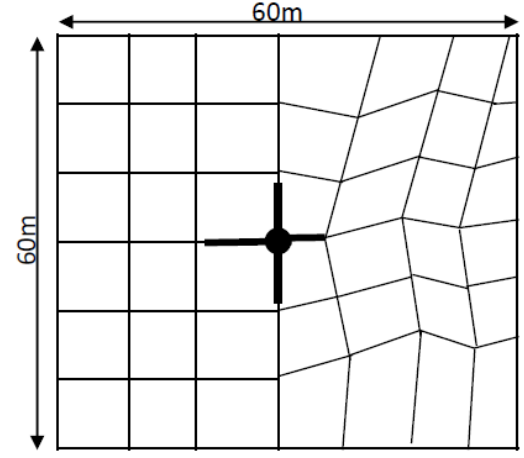

Metric Reach $=250 \mathrm{~m}$

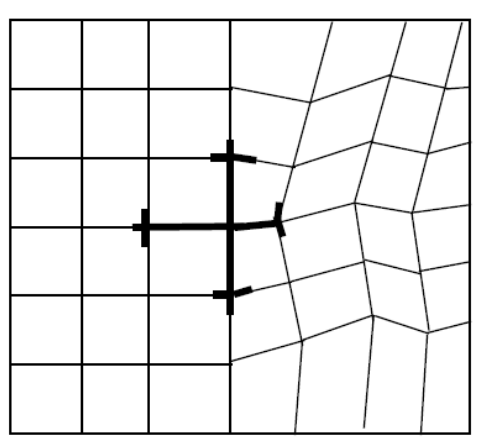

Metric Reach $=600 \mathrm{~m}$

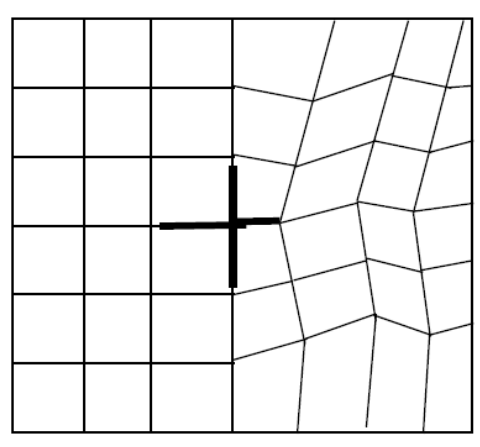

Metric Reach $=1300 \mathrm{~m}$

Distance threshold 
Table 1: Demographic Characteristics $(n=814)$

\begin{tabular}{|c|c|c|}
\hline Characteristic & $\mathrm{n}$ & $\%$ \\
\hline \multicolumn{3}{|l|}{ Gender } \\
\hline Male & 328 & 40.3 \\
\hline Female & 486 & 59.7 \\
\hline \multicolumn{3}{|l|}{ Age group, years } \\
\hline $16-24$ & 56 & 6.9 \\
\hline $25-34$ & 162 & 19.9 \\
\hline $35-44$ & 156 & 19.2 \\
\hline $45-54$ & 132 & 16.2 \\
\hline $55-64$ & 107 & 13.1 \\
\hline $65-74$ & 101 & 12.4 \\
\hline $75+$ & 100 & 12.3 \\
\hline \multicolumn{3}{|l|}{ Annual personal income ${ }^{a}$} \\
\hline$<£ 12,000$ & 263 & 37.5 \\
\hline$£ 12,001-f 30,000$ & 257 & 36.6 \\
\hline$>£ 30,001$ & 182 & 25.9 \\
\hline \multicolumn{3}{|l|}{ Number of vehicles access to } \\
\hline 0 & 228 & 28.0 \\
\hline 1 & 360 & 44.2 \\
\hline $2+$ & 226 & 27.7 \\
\hline \multicolumn{3}{|l|}{ Multiple Deprivation Measure } \\
\hline 1 - most deprived & 226 & 27.8 \\
\hline 2 & 228 & 28.0 \\
\hline 3 & 234 & 28.7 \\
\hline 4 - least deprived & 126 & 15.5 \\
\hline $\begin{array}{l}\text { Physical activity (mins/week active } \\
\text { travel) (median } \pm \text { IQR) }\end{array}$ & 90 & 251 \\
\hline
\end{tabular}

${ }^{a}$ Data not complete for all cases $(\mathrm{n}<814)$. 
Table 2: Connectivity measures for in PARC Study area, Mean and standard deviation centred on survey partipant home address $(n=814)$

\begin{tabular}{|c|c|c|c|}
\hline $\begin{array}{l}\text { Measure of } \\
\text { Connectivity }\end{array}$ & Description & $\begin{array}{l}5 \text { minute buffer } \\
\text { (Mean } \pm S D)\end{array}$ & $\begin{array}{l}10 \text { minute buffer } \\
\text { (Mean } \pm S D)\end{array}$ \\
\hline $\begin{array}{l}\text { Intersection } \\
\text { (Node) } \\
\text { Density }\end{array}$ & $\begin{array}{l}\text { Calculated for } 5 \mathrm{~min}(500 \mathrm{~m}) \text { catchment and } 10 \mathrm{~min}(1000 \mathrm{~m}) \text { catchment } \\
\text { (using Real Walkable Network) from home address of survey participants } \\
\text { living within } 1000 \mathrm{~m} \text { buffer of the Connswater Community Greenway. Area of } \\
\text { catchment divided by number of } 3 \text {-legged nodes within the area of the } \\
\text { respective catchment. }\end{array}$ & $\begin{array}{l}0.000785 \\
\text { (Intersections per } \\
\mathrm{km}^{2} \text { ) } \\
\pm 0.000438\end{array}$ & $\begin{array}{l}0.000686 \\
\text { (Intersections per } \\
\mathrm{km}^{2)} \\
\pm 0.000328\end{array}$ \\
\hline $\begin{array}{l}\text { Link-Node } \\
\text { Ratio }\end{array}$ & $\begin{array}{l}\text { Calculated for } 5 \mathrm{~min}(500 \mathrm{~m}) \text { catchment and } 10 \mathrm{~min}(1000 \mathrm{~m}) \text { catchment } \\
\text { (using Real Walkable Network) from home address of survey participants } \\
\text { living within } 1000 \mathrm{~m} \text { buffer of the Connswater Community Greenway. } \\
\text { Number of links (elements) of network in ratio to the number of 3-legged } \\
\text { nodes within the respective catchment. }\end{array}$ & $\begin{array}{l}0.532 \text { (ratio) } \\
\pm 0.021\end{array}$ & $\begin{array}{l}0.551 \text { (ratio) } \\
\pm 0.012\end{array}$ \\
\hline $\begin{array}{l}\text { Pedestrian } \\
\text { Route } \\
\text { Directness }\end{array}$ & $\begin{array}{l}\text { Distance from home address of survey participants living within } 1000 \mathrm{~m} \\
\text { buffer of the Connswater Community Greenway to nearest park gate, using } \\
\text { the Real Walkable Network. }\end{array}$ & $\begin{array}{l}1.50 \text { (ratio) } \\
\pm 0.44\end{array}$ & $\begin{array}{l}1.50 \mathrm{~km} \text { (ratio) } \\
\pm 0.44\end{array}$ \\
\hline Pedshed (\%) & $\begin{array}{l}\text { Percentage of } 500 \mathrm{~m} \text { and } 1000 \mathrm{~m} \text { buffer represented by catchment of same } \\
\text { distance defined by catchment using the Real Walkable Network, from home } \\
\text { address of survey participants living within } 500 \mathrm{~m} \text { buffer of the Connswater } \\
\text { Community Greenway. }\end{array}$ & $\begin{array}{l}43.39 \% \\
\pm 0.10 \%\end{array}$ & $\begin{array}{l}44.23 \% \\
\pm 0.12 \%\end{array}$ \\
\hline Metric Reach & $\begin{array}{l}\text { Total pathway length of network covered by } 5 \text { min walk }(500 \mathrm{~m}) \text { catchment } \\
\text { and } 10 \mathrm{~min}(1000 \mathrm{~m}) \text { walk in every direction using Real Walkable Network } \\
\text { from home address of survey participants living within } 1000 \mathrm{~m} \text { buffer of the } \\
\text { Connswater Community Greenway. }\end{array}$ & $\begin{array}{l}16.620 \mathrm{~km} \\
\pm 8.488 \mathrm{~km}\end{array}$ & $\begin{array}{l}62.735 \mathrm{~km} \\
\pm 31.207\end{array}$ \\
\hline $\begin{array}{l}\text { Directional } \\
\text { Reach (m) }\end{array}$ & $\begin{array}{l}\text { Total pathway length of network covered by } 5 \text { min walk }(500 \mathrm{~m}) \text { catchment } \\
\text { and } 10 \mathrm{~min}(1000 \mathrm{~m}) \text { walk in every direction, limited by no more than two } \\
\text { changes in direction of more than } 20^{\circ} \text {, using Real Walkable Network from } \\
\text { home address of survey participants living within } 1000 \mathrm{~m} \text { buffer of the } \\
\text { Connswater Community Greenway. }\end{array}$ & $\begin{array}{l}15.97 \mathrm{~km} \\
\pm 20.76 \mathrm{~km}\end{array}$ & $\begin{array}{l}15.97 \mathrm{~km} \\
\pm 20.76 \mathrm{~km}\end{array}$ \\
\hline
\end{tabular}


Table 3: Spearman's Rank Correlation - Associations between measures of connectivity (1000 m buffer) ( $n=814)$

\begin{tabular}{|c|c|c|c|c|c|c|c|c|c|c|c|c|}
\hline \multirow{2}{*}{$\begin{array}{c}\text { Connectivity } \\
\text { measure }\end{array}$} & \multicolumn{2}{|c|}{$\begin{array}{l}\text { Intersection } \\
\text { Density }\end{array}$} & \multicolumn{2}{|c|}{ Ped Shed } & \multicolumn{2}{|c|}{$\begin{array}{l}\text { Link Node } \\
\text { Ratio }\end{array}$} & \multicolumn{2}{|c|}{$\begin{array}{c}\text { Pedestrian } \\
\text { Route } \\
\text { Directness }\end{array}$} & \multicolumn{2}{|c|}{ Metric Reach } & \multicolumn{2}{|c|}{$\begin{array}{l}\text { Directional } \\
\text { Reach }\end{array}$} \\
\hline & $\begin{array}{l}5 \mathrm{~min} \\
(\mathrm{p} \\
\text { value) }\end{array}$ & $\begin{array}{l}10 \mathrm{~min} \\
\text { ( } \mathrm{p} \\
\text { value) }\end{array}$ & $\begin{array}{l}5 \mathrm{~min} \\
(\mathrm{p} \\
\text { value) }\end{array}$ & $\begin{array}{l}10 \mathrm{~min} \\
(\mathrm{p} \\
\text { value })\end{array}$ & $\begin{array}{l}5 \mathrm{~min} \\
\text { ( } p \\
\text { value) }\end{array}$ & $\begin{array}{l}10 \mathrm{~min} \\
(\mathrm{p} \\
\text { value })\end{array}$ & $\begin{array}{l}5 \mathrm{~min} \\
\text { ( } p \\
\text { value) }\end{array}$ & $\begin{array}{l}10 \mathrm{~min} \\
\text { ( } p \\
\text { value) }\end{array}$ & $\begin{array}{l}5 \mathrm{~min} \\
(\mathrm{p} \\
\text { value })\end{array}$ & $\begin{array}{l}10 \mathrm{~min} \\
(\mathrm{p} \\
\text { value) }\end{array}$ & $\begin{array}{l}5 \mathrm{~min} \\
\text { ( } p \\
\text { value) }\end{array}$ & $\begin{array}{l}10 \mathrm{~min} \\
(\mathrm{p} \\
\text { value) }\end{array}$ \\
\hline $\begin{array}{l}\text { Intersection } \\
\text { Density }\end{array}$ & - & - & $\begin{array}{l}0.458 \\
(0.00)\end{array}$ & $\begin{array}{l}0.653 \\
(0.00)\end{array}$ & $\begin{array}{l}0.603 \\
(0.00)\end{array}$ & $\begin{array}{l}0.497 \\
(0.00)\end{array}$ & $\begin{array}{l}-0.312 \\
(0.00)\end{array}$ & $\begin{array}{r}-0.341 \\
(0.00)\end{array}$ & $\begin{array}{l}0.870 \\
(0.00)\end{array}$ & $\begin{array}{l}0.918 \\
(0.00)\end{array}$ & $\begin{array}{c}0.017 \\
(0.633)\end{array}$ & $\begin{array}{c}0.097 \\
(0.005)\end{array}$ \\
\hline Ped Shed & $\begin{array}{l}0.458 \\
(0.00)\end{array}$ & $\begin{array}{l}0.653 \\
(0.00)\end{array}$ & - & - & $\begin{array}{l}0.387 \\
(0.00)\end{array}$ & $\begin{array}{l}0.337 \\
(0.00)\end{array}$ & $\begin{array}{r}-0.440 \\
(0.00)\end{array}$ & $\begin{array}{r}-0.502 \\
(0.00)\end{array}$ & $\begin{array}{l}0.793 \\
(0.00)\end{array}$ & $\begin{array}{l}0.878 \\
(0.00)\end{array}$ & $\begin{array}{l}0.348 \\
(0.00)\end{array}$ & $\begin{array}{l}0.360 \\
(0.00)\end{array}$ \\
\hline $\begin{array}{l}\text { Link Node } \\
\text { Ratio }\end{array}$ & $\begin{array}{l}0.603 \\
(0.00)\end{array}$ & $\begin{array}{l}0.497 \\
(0.00)\end{array}$ & $\begin{array}{l}0.387 \\
(0.00)\end{array}$ & $\begin{array}{l}0.337 \\
(0.00)\end{array}$ & - & - & $\begin{array}{l}-0.212 \\
(0.00)\end{array}$ & $\begin{array}{r}-0.201 \\
(0.00)\end{array}$ & $\begin{array}{l}0.534 \\
(0.00)\end{array}$ & $\begin{array}{l}0.459 \\
(0.00)\end{array}$ & $\begin{array}{l}-0.105 \\
(0.003)\end{array}$ & $\begin{array}{l}-0.113 \\
(0.001)\end{array}$ \\
\hline $\begin{array}{l}\text { Pedestrian } \\
\text { Route } \\
\text { Directness }\end{array}$ & $\begin{array}{l}-0.312 \\
(0.00)\end{array}$ & $\begin{array}{r}-0.341 \\
(0.00)\end{array}$ & $\begin{array}{r}-0.440 \\
(0.00)\end{array}$ & $\begin{array}{r}-0.502 \\
(0.00)\end{array}$ & $\begin{array}{l}-0.212 \\
(0.00)\end{array}$ & $\begin{array}{r}-0.201 \\
(0.00)\end{array}$ & - & - & $\begin{array}{l}-0.425 \\
(0.00)\end{array}$ & $\begin{array}{l}-0.441 \\
(0.00)\end{array}$ & $\begin{array}{l}-0.183 \\
(0.00)\end{array}$ & $\begin{array}{l}-0.183 \\
(0.001)\end{array}$ \\
\hline Metric Reach & $\begin{array}{l}0.870 \\
(0.00)\end{array}$ & $\begin{array}{l}0.918 \\
(0.00)\end{array}$ & $\begin{array}{l}0.793 \\
(0.00)\end{array}$ & $\begin{array}{l}0.878 \\
(0.00)\end{array}$ & $\begin{array}{l}0.534 \\
(0.00)\end{array}$ & $\begin{array}{l}0.459 \\
(0.00)\end{array}$ & $\begin{array}{l}-0.425 \\
(0.00)\end{array}$ & $\begin{array}{l}-0.441 \\
(0.00)\end{array}$ & - & - & $\begin{array}{l}0.212 \\
(0.00)\end{array}$ & $\begin{array}{l}0.229 \\
(0.00)\end{array}$ \\
\hline $\begin{array}{l}\text { Directional } \\
\text { Reach }\end{array}$ & $\begin{array}{c}0.017 \\
(0.633)\end{array}$ & $\begin{array}{c}0.097 \\
(0.005)\end{array}$ & $\begin{array}{l}0.348 \\
(0.00)\end{array}$ & $\begin{array}{l}0.360 \\
(0.00)\end{array}$ & $\begin{array}{l}-0.105 \\
(0.003)\end{array}$ & $\begin{array}{l}-0.113 \\
(0.001)\end{array}$ & $\begin{array}{r}-0.183 \\
(0.00)\end{array}$ & $\begin{array}{r}-0.183 \\
(0.00)\end{array}$ & $\begin{array}{l}0.212 \\
(0.00)\end{array}$ & $\begin{array}{l}0.229 \\
(0.00)\end{array}$ & - & - \\
\hline
\end{tabular}

Table 4: Spearman's Rank Correlation - association between physical activity (mins active travel/week) and connectivity ( $\mathrm{n}=814$ )

\begin{tabular}{|c|c|c|c|c|}
\hline \multirow{2}{*}{$\begin{array}{l}\text { Connectivity } \\
\text { Measure }\end{array}$} & \multicolumn{2}{|c|}{5 min walk buffer } & \multicolumn{2}{|c|}{10 min walk buffer } \\
\hline & $\begin{array}{l}\text { Correlation } \\
\text { coefficient }\end{array}$ & $P$ value & $\begin{array}{l}\text { Correlation } \\
\text { coefficient }\end{array}$ & P value \\
\hline $\begin{array}{l}\text { Intersection } \\
\text { Density }\end{array}$ & 0.123 & $0.00^{* *}$ & 0.143 & $0.00^{* *}$ \\
\hline Ped Shed & 0.066 & $0.035^{*}$ & 0.102 & $0.001^{* *}$ \\
\hline Link Node Ratio & 0.056 & 0.071 & 0.051 & 0.099 \\
\hline $\begin{array}{l}\text { Pedestrian Route } \\
\text { Directness }\end{array}$ & -0.064 & $0.039^{*}$ & -0.064 & $0.039^{*}$ \\
\hline Metric Reach & 0.120 & $0.00^{* *}$ & 0.132 & $0.00^{* *}$ \\
\hline Directional Reach & 0.045 & 0.151 & 0.045 & 0.151 \\
\hline \multicolumn{5}{|c|}{$\begin{array}{l}{ }^{* *} \text { Correlation is significant at the } 0.01 \text { level (2-tailed) } \\
{ }^{*} \text { Correlation is significant at the } 0.05 \text { level (2-tailed) }\end{array}$} \\
\hline
\end{tabular}

